\title{
OS TRATADOS DE ARQUITETURA DO SÉCULO XVIII: DESENVOLVIMENTO E DIFUSÃO DE CONHECIMENTO DA ARTE DA CANTARIA
}

\author{
Daniela Viana Leal \\ Instituição: Unicamp - doutorado em andamento sob orientação do Prof. \\ Dr. Marcos Tognon.
}

De um modo geral, na língua portuguesa, o termo "cantaria" se associa à pedra de canto, esquadrejada ou talhada, elemento de finalização nos ângulos das construções em pedra.

Para Segurado ${ }^{1}$ :

A cantaria é a pedra aparelhada utilizada em paredes, socos, faixas, cimalhas, ombreiras, vergas, peitoris, soleiras, etc, a argamassa serve apenas para ligar as pedras entre si pelos seus leitos e demais superfícies de contato.

E assim a diferencia da Alvenaria:

A alvenaria é a pedra toscamente partida, ligada por argamassa em grande quantidade que lhe serve de ligante e ao mesmo tempo de almofada, para assentar em cheio, sobre as pedras já colocadas. Aplica-se nos mesmos casos que a cantaria, mas é indispensável guarnecer a sua superfície com um reboco para a tornar lisa.

E para Bazin², ao se referir às condições técnicas das construções religiosas do período barroco brasileiro:

A Alvenaria é uma espécie de cascalho bem grosseiro, no qual, com freqüência, estão misturados na argamassa toda espécie de elementos, não somente pedras, mas também tijolos, sendo que, no princípio, a argila crua era usada como aglutinante (...). $\mathrm{O}$ uso de cantaria era reservado às partes nobres do edifício, que necessitavam de molduragem: frontispício, pilastras, soleiras, peitoris, umbrais e parapeitos de portas e janelas, cornijas e faixas.

Boa parte das mais nobres obras arquitetônicas do século XVIII construídas em decorrência da descoberta de ouro na região de Minas Gerais, portanto, utiliza a arte da cantaria. Todavia, a importância desse método construtivo e dessa atividade, ainda não é considerada como elemento fundamental na preservação. Muitas obras são reformadas hoje

\footnotetext{
${ }^{1}$ SEGURADO, João Emilio dos Santos, Alvenaria e Cantaria, Lisboa: Bertrand, 1908

2 BAZIN, Germain. A Arquitetura Religiosa Barroca no Brasil, Rio de Janeiro: Record, 1983.
} 
em dia utilizando técnicas anacrônicas como o concreto armado para substituir peças de cantaria, em boa medida por falta de conhecimento e parâmetros para poder produzir outras peças corretamente 3 .

No passado, a difusão do conhecimento técnico estava restrita a poucos textos disponíveis de divulgação muito limitada, e se apoiava em um número restrito de construções exemplares que serviam de modelos. Durante a chamada Idade Média esses conhecimentos ficavam restritos a regras internas das corporações de ofício vinculadas ao segredo verbal. A formação de um aprendiz era feita em diversos estaleiros ou fábricas aprendendo diretamente com o mestre.

No século XVIII, entretanto, conhecido como século das luzes, essa situação muda. A produção editorial é intensificada inclusive na área da construção. Entre 1680 e 1780 houve uma multiplicação por 10 dos estoques de livros na Europa ocidental ${ }^{4}$.

Os Tratados de Arquitetura do período apresentam características próprias a respeito de estabelecimento de parâmetros e de difusão de conhecimentos. Eles atendem a uma nova demanda de apreciação e a uma nova forma de compreender a importância do trabalho manual.

A racionalidade iluminista leva os estudos matemáticos ao campo das artes e ofícios ${ }^{5}$. A teoria da arquitetura concebe o edifício como geometria e volta-se para normas estruturais de composição.

A postura do Iluminismo gera uma revolução no pensamento europeu. O estímulo da dúvida sistemática e busca de explicação dos fenômenos pela Matemática valorizam o inteligível sobre o sensível. O estudo das artes e ciências passa a se dar de maneira mais metódica do que curiosa.

Ocorre a catalogação das diversas ciências estabelecidas em publicações em forma de dicionários e de enciclopédicas. Elas estão vinculadas ao processo de especialização e desenvolvimento autônomo de vários domínios de conhecimento.

\footnotetext{
${ }^{3}$ Apresentamos exemplos desse tipo de atitude perante o patrimônio construído em: LEAL, Daniela Viana. A arte da Cantaria ao longo da Estrada Real - as produções do século XVIII no caminho do ouro em abordagens multidisciplinares. Campinas: Anais do II Encontro de História da Arte da Unicamp, 2006.

${ }^{4}$ OLIVEIRA, Myriam Andrade de. O Rococó Religioso no Brasil e seus antecedentes europeus. São Paulo: Cosac \& Naify, 2003.

${ }^{5}$ PEVSNER, Nikolaus. Academias de Arte: passado e presente. São Paulo: Companhia das Letras, 2005.
} 
Várias novas escolas e academias são fundadas nesse século ${ }^{6}$. Muitos tratados publicados nesse período são desenvolvidos por professores dessas instituições como meio de divulgar suas descobertas e propostas e mesmo como textos de acompanhamento de aulas.

No caso da Cantaria, a disciplina que já passava por um processo de autonomia desde a Idade Média e que avança extraordinariamente durante o Renascimento, nesse momento, vincula-se com ainda mais força às artes matemáticas.

São publicadas várias edições de livros sobre aritmética e geometria fundamentais que eram utilizados na formação de mestres e construtores para capacitá-los a efetuar cálculos, desenhar planos e realizar projetos.

Alguns deles eram reimpressões de séculos anteriores. Outros, mesmo não sendo reimpressos aparecem sempre em citações, o que leva a crer que eram conservados e passados à próxima geração, refletindo assim também a técnica usada no século seguinte.

Um bom exemplo disso é a obra do padre agustino e mestre de obras madrileno Fray Lorenzo de San Nicolas "Arte y Uso de Arquitectura" do século XVII. A linguagem simples de seu texto rendeu diversas críticas dos colegas acadêmicos, mas garantiu uma grande divulgação entre os mestres construtores inclusive nas terras americanas para onde exemplares foram levados pelos missionários.

Da mesma forma, a obra mais conhecida de Vignola 7 expõe de maneira elementar e rápida os tecnicismos das cinco ordens, sem excessos de retórica. Além disso, por indicar de maneira sintética suas medidas e a representação gráfica de cada uma delas com belos desenhos, o autor conseguiu garantir que as proporções sugeridas obtivessem ampla aceitação.

\footnotetext{
${ }^{6}$ Em Portugal a Academia de Fortificação de Elvas e Almeida (1701); Aulas de Náutica e Desenho no Porto (1762); Cursos de Arquitetura Civil, Militar e Desenho após a reforma pombalina no Colégio dos Nobres de Lisboa (1765-1772); Faculdade de Matemáticas na Universidade de Coimbra (1772); Academia de Ciências de Lisboa (1779). Na França a Sociedade Real de Ciências de Montpelier (1706); Escola de Artes de Paris (1740); Escola Superior de Minas em Paris (1778). Na Itália Academia de Ciências do Instituto de Bologna (1710); Academia de Belas Artes de Veneza (1750); Academia de Ciência de Turim (1757); Academia de Belas Artes de Milão (1776). Na Espanha a Real Academia Espanhola de Madri (1713); Real Escola de Matemática Militar de Barcelona (1716). Na Inglaterra a Real Academia de Artes (1768); Sociedade dos Engenheiros Civis (1771). No Brasil temos a Ala do Terço e a Aula do Regimento de Artilharia do Rio de Janeiro, com José Pinto Alpoim (1738). Para um quadro mais geral ver: MATEUS, João Mascarenhas. Técnicas tradicionais de construção de alvenarias - a literatura técnica de 1750 a 1900 e o seu contributo para a conservação de edifícios históricos. Livros Horizonte, Coleção Cidade de Lisboa, 2002.

${ }^{7}$ VIGNOLA, Jacomo Barozzi. Regola delle cinque ordini, 1562.
} 
Seus textos foram reimpressos e serviram de socorro para construtores no mundo todo.

Como exemplo oposto, para compreender a mudança de postura dos tratados do século XVIII, podemos apresentar o livro do francês Mathurin Jousse 8 . Com o conveniente título "Le secret d'architecture..." ele apresenta problemas elementares de geometria, noções de ordem de arquitetura, questões de estereotomia, de forma tão hermética e confusa, que mantêm a idéia de segredo para iniciados.

Já o livro de Derand ${ }^{9}$, publicado no ano seguinte, voltado menos aos eruditos que aos trabalhadores da arquitetura, se torna uma referência em trabalhos posteriores que citam o método Derand. Ao contrário do tratado anterior, participa realmente do processo de publicação dos segredos da cantaria. Seu foco não é apresentar novas soluções, mas sim uma compilação organizada dos saberes e conhecimentos práticos e empíricos dos mestres de então com grande cuidado gráfico e abundância de anotações nas figuras.

O tratado de Philibert Delorme, considerado o mais importante arquiteto do renascimento na França ${ }^{10}$, foi publicado em Paris em 156711 e apresentado por Rovira y Rabassa12 como "primeiro autor que há escrito sobre esta matéria". Sua postura em relação aos clássicos, especialmente Vitrúvio, é fonte para o conhecimento do período. Ele abertamente afirma que se baseia em Vitrúvio, mas por várias vezes cita a falta de clareza desse texto antigo, ou seja, pretende se possível ir além, torná-lo mais compreensível através de uma versão pessoal. Essa é uma prática muito comum no período onde o autor afirma que o arquiteto deve seguir os antigos, mas ao mesmo tempo, apresenta exemplos de obras do seu período e especialmente a suas próprias.

Livros com comentários e exemplos próprios como os de D. Barbaro, Palladio e Scamozzi abrem caminho para "o conceito de Manual Prático de Arquitetura".

8 JOUSSE, Mathurin. Le secret d'architecture découvrant fidelement les traits geometriques, couppes, et derobemens necessaire dans les bastiments, enrichi d'un grand nombre de figures, adioustées sur chaque discours pour l'explication d'iceux, s/e., 1642

9 Derand, Fraçois. L'architecture des voutes s/ed. 1643.

${ }^{10}$ TAVARES, Domingos. Philibert Delorme Profissão de arquitecto, Porto: Edição Dafne, 2004.

${ }^{11}$ DELORME, Philibert, Le premier tome de l'architecture. Paris: chez Federic Morel, rue S.Jean de Beauvais, 1567

12 ROVIRA y RABASSA, Antonio. Estereotomia de la piedra, Barcelona: Libreria y estamperia Artística, 1897, pag. 136. 
Como o próprio nome indica, eles têm uma característica muito menos acadêmica que os tratados clássicos. São livros direcionados tanto à construção civil quanto à prática militar e de agrimensura.

Podemos usar como exemplo o produzido pelo engenheiro e abade siciliano Giovanni Amico Dott ${ }^{13}$ em cinco volumes. A primeira parte, dedicada à geometria segue os parâmetros de várias outras publicações do gênero com intenções de popularização de conhecimentos acadêmicos. Na segunda parte, (onde trata da edificação, da natureza da arquitetura, da escolha do local, dos ventos, das águas, etc.) discute a respeito dos materiais dos edifícios sendo "prima delle pietre" com suas classificações e suas origens. Além disso, ele faz referências a Palladio, Alberti e Vitrúvio, a respeito das formas de construir com esse material, acompanhadas de figuras e tabelas práticas.

A partir da restauração renascentista das formas clássicas se inicia o processo de acentuar a ornamentação que será interrompido apenas pela moderação acadêmica. $\mathrm{Na}$ arquitetura barroca a criação de novos motivos, seu emprego em profusão e o seu caráter correspondem com as propriedades que definem a estética desse período. A ornamentação complexa intensificava o dinamismo, os efeitos de claro-escuro, a diversidade rítmica, etc. Como os tratados tradicionais de Serlio e Alberti davam poucas informações sobre os ornamentos, a arquitetura romana volta a ser analisada em seus detalhes, como vasos, candelabros, urnas, etc. e gera uma boa quantidade de publicações com recolha de imagens e pranchas ilustradas. Muitos deles se encontram a disposição na Biblioteca Cicognara ${ }^{14}$.

No final do século XVIII a especialização da disciplina chegou a um ponto de autonomia profunda. A teoria era focada nos fundamentos geométricos para cada caso. As figuras eram reduzidas a plantas e vistas em desenhos cada vez mais claros e expressivos das projeções.

\footnotetext{
13 AMICO DOTT, Giovanni. L'architetto Prattico in cui com facililta si danno le regole per apprendere l'architettura civile, Palermo, 1726

${ }^{14}$ Trata-se de um acervo com mais de 40 mil microfichas, que reproduzem cinco mil títulos que pertenceram à biblioteca particular do Conde Francesco Cicognara (1767-1834). Ele, além de crítico, foi historiador da arte, bibliófilo e pintor. $\mathrm{O}$ acervo original e físico pertencente à Biblioteca Apostólica Vaticana, mas foi reproduzido pela Universidade de Illinois, que o colocou à disposição de instituições interessadas. Com o apoio da Fapesp através de Projeto Temático, hoje se encontra acondicionado no setor de Obras Raras da Biblioteca Central da Unicamp.
} 
No final do século XVIII, o engenheiro de francês Gaspard Monge ${ }^{15}$ garante, com seu livro sobre a geometria descritiva, a unificação dos critérios gráficos e a abstração dos procedimentos.

A estereotomia era entendida não apenas como o corte da pedra ou cantaria, mas como todo um conjunto de conhecimentos e estratégias de geometria prática. Nos tratados a palavra aparece para discriminar uma disciplina autônoma e articulada.

O próprio uso do neologismo grego (estereo - sólido e tomos - corte) expressa a atitude e vontade cientificista que acabará por converter a disciplina em especialidade da geometria.

Algumas publicações chegam a um tamanho grau de perfeccionismo geométrico que se desvinculavam da realidade da obra. $\mathrm{Na}$ França, autores como Frezier ${ }^{16}$ apresentam tratados teóricos repletos de tabelas e índices pormenorizados. A preocupação e admiração pelas formas geométricas simples ou regulares em detrimento das derivadas dos métodos tradicionais da talha desses autores levam a uma ruptura que separará a estereotomia do século XIX da tradição anterior.

...

Não podemos afirmar que as técnicas ou as formas utilizadas nas fábricas dos mestres canteiros ou na produção arquitetônica em pedra setecentistas mineira seguissem exatamente um determinado modelo difundido em um tratado específico. Todavia, a análise do conjunto de publicações sobre esse tema no período delimitado nessa investigação indica quais os vocabulários técnicos e formais circulavam entre os profissionais tanto da metrópole quanto da colônia.

Essas publicações precisam ser encaradas dentro do universo artístico, histórico e cultural no qual foram criadas para evitar anacronismos e simplificações superficiais. Essas fontes servem para perceber como a técnica se desenvolveu e como era difundida, e assim, gerar subsídios para compreender melhor essa arte tão importante para a formação do patrimônio setecentista nacional e tão pouco conhecida mesmo entre os profissionais da área.

\footnotetext{
${ }^{15}$ MONGE, Gaspard. Geometrie Descriptive. Paris: Badouin, 1799.

${ }^{16}$ FREZIER, AMÉDEÉ-François. Elements de stéréotomie..., Paris: Jombert, 1760.
} 